\title{
Creative Aproduction: Mucous and the Blank
}

\section{Patricia MacCormack and Ruth McPhee}

This article will be catalysed by mucous in order to think a form of abstracted queer ahuman "heterosexuality". As mucous is neither gendered nor emitted from a specific corporeal site, it is effulgent, viscous emergence without finitude. The article will suggest that a hitherto fluidic symbol of finitude - male ejaculate - can be liberated from the conceptual apprehension conveyed in its nomenclature through the figure of the vasectomised male body. We argue that a comingling of abstract feminine fluid and male fluid abstracted from its need for spermatozoa content is a creative act which avoids the foils of heterosexuality's resonance with reproduction, both of act and human procreation. This is a radical anti-breeder project seeking to liberate the ecosophical chaos, the virtual potentiality of all interrelated elements of life in nature, from the parasite of the human and its continuation, in a broader sense, vasectomised ejaculate affirms an ahuman sexuality which demands a confrontation with the horror of the non- or anti-breeder male, and with the act of love for the chaosium, a mucosal plane formed of intermixed feminine fluid and the discharge of potent blanks.

Whatever "fluid" ultimately comes from the penis, its various manifestations have most often been reduced to a nomenclatorial object, a demarcated, singular phenomenon which extricates it from its relation with other elements and with the fluidity that would identify it for its metamorphic rather than atrophied and thus symbolic or even iconic status. This occurs in two ways. First, the "money shot" refines the molecular, fractured multiplicity of spatter to a single signifier of outcome or production, in spite of its genesis in spasm and schizophrenic flux which begins far in advance of its visually apprehensible emergence and continues beyond its final perceptible globularity. The cultural imagination of semen as a visible substance centres around its appearance on skin, hands, breasts, faces: white, shiny and sticky, it is reduced to spectacle, its mucosal tangibility put to service within the economy of the specular. 
Second, semen is understood frequently as a collection of hard-headed and intentional little wills in the form of spermatozoa, in spite of their only composing between two and five percent of the fluid (http://en.wikipedia.org/wiki/Semen) in whatever apocryphal phenomenon one calls an "average male". Here lies the fantasy of familiar little figures dancing within a Petri dish, magnified for our scrutiny, subjected to the processes of identification, and rendered semen according to the human (il)logic of anthropomorphism and homogenisation. Resonant with this over-privileging of the notion of "population" to the fluid is the common ascription of the fluid's origin as in the testes. In fact, only the spermatozoa are produced there; the seminal vesicle, prostate and bulbourethral glands are also crucial facilitators of semen production, however, these organs have been deferred, subjugated to the organisation of masculinity around the testes.

Even in the most generic encyclopaedic definitions of semen, each other element of seminal fluid from the chemical compounds, amino acids, enzymes and antigens to the mucous - is defined via its assigned function to facilitate the life, energy, mobility and thus goal orientation of the sperm. Semen, therefore, is regarded simply as a facilitator and is only in extremely rare circumstances considered uncoupled from this reproductive aim. While sperm does offer an impasse in its multiplicity within the solidification of ejaculate, it nonetheless remains, in spite of its microscopic plenitude, culturally overrepresented as a smooth, rounded, microcosmic phallus with a tail, perpetuating the persistent visualisation of pleasure through objects, surfaces and enclosed forms.

This operation goes against philosophies of vitalism and the call to thought as opposed to knowledge, the latter acting as a corrupting excavation toward annihilation. Leonard Lawlor states:

the ground must never resemble what it grounds. If the ground resembles, if it is copied off what it grounds, then we have used precisely what we are trying to explain in the explanation. Instead of resemblance, we must conceive the relation between the two poles, we must conceive the écart, as conflict. As conflict, the interweaving, the "folding over" becomes " the unfold"; the "place" becomes " spacing"; the milieu becomes the "nonplace". (2006, p. 146)

Through Michel Serres we are reminded that this conflict is not antagonistic; rather, it buttresses necessary differences within and between each other, allowing each specificity and the specificity 
of combinations temporally and temporarily, and avoiding stable or final categorisations. Serres writes: "When encounters and connections occur, bodies are characterized according to their resistance" (2000, p. 5). Making sperm resonate with the phallic head, giving both an object of desire (egg and aperture), a function, and directing pleasure toward the finitude of the money shot, all come together to create a relationship of proportionality between sperm and phallus. This correspondence repudiates any possible liberation in the plenitude, frequent deformity and alternate swimming trajectories that many sperm exhibit; the cultural fantasy of perfectly formed and functional "little men" leaves no place for abnormal sperm morphology or sluggish swimmers. Luce Irigaray asks: "Isn't the subjection of sperm to the imperatives of reproduction alone symptomatic of a pre-eminence historically allocated to the solid (product)?" (1985, p. 113). The possibility of a child continues the zones of resonance between: the wilful solid, hard sperm; the intentional and turgid phallus; the production of a new subjectivity through reproduction; and the paradigmatic privileging of associated elements of the visual, the demarcated and the reified as the driving tenets of phallologocentrism, the grounds of which notoriously produce what orients them in an elliptical rhetoric that vindicates its power - another hard-headed effect.

Lee Edelman has vehemently argued that the image of the futuristic Child (a figure of fantasy rather than reality) structures not only the social but also necessarily the political:

That logic compels us, to the extent that we would register as politically responsible, to submit to the framing of political debate - and, indeed, of the political field - as defined by the terms of what he describes as reproductive futurism: terms that impose an ideological limit on political discourse as such, preserving in the process the absolute privileging of heteronormativity by rendering unthinkable, by casting outside the political domain, the possibility of a queer resistance to this organizing principle of communal relations. (2004, p. 2)

This "reproductive futurism" is seen across all forms of socio-cultural discourse: literature, party politics, science, media, philosophy, psychology. Edelman attests that as a defining structure it has been used to maintain damaging definitions of "correct" or "good" desire and to refute all political and ethical perspectives that do not ultimately revolve around this imaginary figure. Building upon this, it also serves to configure certain types of corporeal experiences as valid and others as invalid, 
including those around male/female couplings that may actively refute the reproductive aim. Although Edelman is primarily concerned with the place of homosexuality within politics and culture, and whilst his polemical call for queerness to celebrate its equation with "the social order's death drive" (2004, p. 3) is certainly problematic to some extent, the concept of reproductive futurism remains useful because it offers an insight into the structural processes that still dominate thinking about sexual difference and the place of gendered bodies. The call to embrace the previously denigrated "ascription of negativity to the queer" within heteronormative culture (2004, p. 4) posits the denial of reproductive futurity and the making of the male body infertile as deliberate acts and creative choices. Additionally, it raises the frequently disavowed possibility of a future not only without the Child as idealised symbol or "perpetual horizon of every acknowledged politics" (2004, p. 3) but also without humanity in any form at all, symbolic or otherwise. Reproductive futurity assumes the perpetuation of the human race as an unquestionable given and an intractable ethical imperative. Aproduction argues that these assumptions are crucially flawed and that challenging them remains one of the most pressing concerns for philosophical thought.

This may also be thought in relation to Felix Guattari's ecosophy, a new ethico-political claim that recognises the need to reinvent collective and individual practices within the realms of social relations, human subjectivity (or mental ecology) and the environment. Guattari affirms, "[m]ental ecosophy will lead us to reinvent the relation of the subject to the body, to phantasm, to the passage of time, to the "mysteries of life and death" (2004, p. 24) The image of the child that dominates reproductive futurism is indeed a totalising phantasm that haunts majoritarian notions of corporeality and temporality, aiming to satisfy the narcissistic humanist demand to live forever through the continuation of both specific familial genealogies and the human race as a whole. True engagement with and take responsibility within this ecosophical example requires a paradigmatic shift in how culture and society view human subjectivity and human sexuality through the prism of reproduction; it calls for the need to "kick the habit of sedative discourse" (Guattari, 2004, p. 29). For this reason, the act of producing an infertile male body may be seen not as a "reduction", but as part of a process of reinvention that lies at the heart of the ecosophical project. Via this logic then, if we cut off the equivalences between spermatozoa and the penis, we are left with a different kind of organ, where the fluidity of ejaculate is not premised on sperm but on its singularity without utility, potentialisation of reproduction, or equivalence with the orientations of the phallic structurisation of masculinity. 
Irigaray asks: "Must we then understand this modelling function - more or less hidden from view of the object of desire as resulting from the passage, a successful one, from the fluid to the solid state? The object of desire itself, and for psychoanalysts would be the transformation of fluid to solid" (1985, p. 113). Aristotle's observations about semen in The Generation of Animals confirm Irigaray's assertion and further elucidate the dynamics that emerge in relation to fluids, solids and the rethinking of sexual difference outside binary schemata. A perhaps surprising amount of space in Aristotle's text is devoted to the exploration of the nature and purpose of seminal fluid, and there certainly seems to be some investment in the distinction and elevation of this bodily secretion over all others. After ruminating at length Aristotle comes to the conclusion that semen may be described as "part of a useful residue" deriving from a fluid (1943, p. 80), placing the onus upon its co-option into utility above all else. Further entrenching his subject within the rigid binary of the mechanics of reproduction, he draws an equivalence between semen and menstrual blood: "Thus much then is evident: the menstrual fluid is a residue, and it is the analogous thing in females to the semen in males" (p. 95).

Such a clumsy equivalence occludes any possibility of the non-reproductive mixing of seminal mucous with cervical mucous and ignores the potentialities of desire and pleasure that such mucosal minglings bring into effect; instead, it affixes heterosexual bodies and their secretions into one oppositional framework that remains resolutely gendered and functional. Aristotle's further assertion that the crucial difference between semen and menstrual fluid is that the semen acts as a vehicle for as the "sentient 'Soul'" (p. Ixvii) works to organise these genders hierarchically. Although he may acknowledge fluidity in terms of origins, the conceptual passage from fluid to solid that Irigaray observes as a both a primary function and foundational desire of phallologocentric thought is clearly apparent in Aristotle's text. For him, semen is hot, shiny and white, but also "coherent" (1943, p. 161). Whilst he uses this word to refer to the material properties of viscosity and texture, it also carries further connotations of fixed taxonomy and stable signification. In order to rethink ejaculate and the non-reproductive heterosexual encounter outside hierarchical and oppositional frameworks, such notions of "coherent", stabilised meanings and pre-determined endings must be cast aside, leaving space for an agendered form of masculine corporeality based around fluidity. 
Utilising a physics of fluids to think through desire understands male ejaculate differently, "[t]he flux of the atomic insemination flows by the feminine clinamen" (Serres, 2000, p. 39). The very premise of bodily fluids most immediately invokes Julia Kristeva's work on abjection. In Leviticus, semen is unclean:

When a man has an emission of semen, he must bathe his whole body with water, and he will be unclean till evening. Any clothing or leather that has semen on it must be washed with water, and it will be unclean till evening. When a man has sexual relations with a woman and there is an emission of semen, both of them must bathe with water, and they will be unclean till evening. (15:16-18)

However, Kristeva claims that "neither tears nor sperm, for example, although they belong to the borders of the body, have any polluting value" (1982, p. 71). While the value of evening in purifying the polluting effects of fluids remains enigmatic, there is a clear impasse between what seminal fluid is and what it contains; the semantics of language (beyond the scope of this article) in reference to this understanding, and various translations of "sperm" and "semen" can broadly be classified as the bifurcation between solid and fluid.

This also emphasises the cultural fantasies invested in the imaginings of sperm, as it is doubtful that the hyper-glorification of the visually-manifested money shot in pornography is one which directly apprehends each sperm and would thereby constitute a world where the greatest virility was measured not on the rigidity or size of the penis but upon the plethora and directionality of one's sperm. Again we see an impasse which shows the confounding nature of the conflict between semen and its content (or lack thereof): the purpose of the money shot is to transform pleasure to solid evidence; desire for the woman converts into desire for the evidence which authenticates the pleasure. The function of sperm in pornography is rendered defunct; the proximity of sperm to the uterus is an anathema to the privileging of its visual incarnation contrasted against whatever makes it most conceptually, and therefore impossible to be actually, reproductively virile. Put simply, if the money shot is outside of the cervix, the function of insemination for reproduction is unlikely. This impasse points towards paradoxical cultural fantasies concerning the positionality of semen - its interiority and exteriority in relation to the body. In order for the apparent goal to be achieved, semen must remain always inside, moving between the 
male body and the female body without providing specular evidence of its existence. Yet this specular evidence is precisely what is demanded and must be repeatedly provided in cultural representations.

These many circles of atrophying fluidities of pleasure, secretions, mucous and flow, and their subordination to the solid and its associated visualisation, suggest that the attempt to exploit the fluidity of male sexuality and semen-ality hinges primarily on strategies of extrication and demarcation - between the sexes, between bodies, and within the fluids which, by their very fluidity, threaten the mechanics of solids which perpetuate phallologocentrism. Irigaray, Kristeva and Leviticus all defer to the conundrum that, according to Murat Aydemir, "sperm can apparently be both clean and dirty, and, moreover, can take part in an immanent rapture that can be "injoyed", yet not known" (207, p. xxii). But there is an ethical implication in this argument which may shift it toward a more radical vitalism still - a vitalism that concerns itself with life as it is rather than the lives to be. What happens when, rather than oscillating between the ambiguities of sperm being both clean and unclean, phallic and multiple, we remove sperm altogether? Is sperm perhaps a useful "solid" to extricate in order to explore both a sexually fluid male pleasure and a queer heterosexuality denied any residual phantasies of reproductive potential?

Sperm can be seen to parasite the far greater volume of non-sperm fluid which surrounds it, just as the constantly reproducing human population parasites the host earth. Serres states:

in its very life and by its practices the parasite routinely confuses use and abuse; it accords itself rights, which it exercises by harming its host, sometimes without any advantage for itself. The parasite would destroy the host without realising it. Neither use nor exchange has value in its eyes, for it appropriates things - one could say that it steals them - prior to use or exchange: It haunts and devours them. The parasite is always abusive. ... For parisitism, in fact, follows the simple arrow of a flow moving in one direction but not the other, in the exclusive interest of the parasite, which takes everything and gives back nothing in this one-way street. $(2002$, p. 36) 
Particularly in the case of heterosexual intercourse which is adverse to reproduction, the sperm as parasite both haunts the flows of pleasure and gains no benefit for itself. Sperm as possible catalyst for reproduction does not simply abuse the semen as a product of orgasm but turns it into a product. Semen has no necessary relation with orgasm, nor with its precursory fluids and subsequent dribbles. Sperm and the intentionality of orgasm makes objects of both semen and desire, parasiting pleasure, atrophying the sensitive epithelium male genital area into host to phallic phantasies and the testicles into the site of masculine organisation. the common characterisation of their single flow of desire to object, their sexual aim, and their goal of orgasm and occasionally production of a human results from the ways in which sperm has come to be the primary microcosmic template in the resonant macrocosmic cultural homogenisation of heterosexual intercourse based on paradigms of single focus, aim, goal, direction and production. This disregards the myriad constellations of infinite potentials and intensities this rather ordinary act can catalyse. Sperm are indeed the little homunculi of the parasitic human they may assist in developing.

Rather than configure the extinction of sperm and humans as nihilistic, however, finitude advocates dissolution of the obsession with eternity through reproduction and simultaneously forges what Gilles Deleuze and Félix Guattari call unnatural participations: "combinations neither genetic nor structural; they are interkingdoms, unnatural participations. That is the only way Nature operates against itself" (1987, p. 242). While, arguably, heterosexual sexual encounters involving what would ordinarily be understood as "normal" sex has the potential to be thought without grounding within reproductivity, majoritarian reproductive tenets will always move to colonise. By taking away this very possibility through the active and deliberate choice to vasectomise the male body, many of those elements associated with phallologocentrism, production and object desire are revoked - the penis no longer phallus, seminality without sperm, castration, female objectification displaced, pleasure no longer subjected to orgasm, antagonism toward the orgasm defined purely through productive value dispersed. It is a question, then, of liberating semen from the parasitical and symbolic constraints which have been placed upon it philosophically and representationally, and exploring the new possibilities that open up for heterosexual desire in the context of this previously unthought corporeality. 
"Both heterosexuality and homosexuality are the precarious outcome of a desire which knows no name. If the distinction between biology and psychology thus disappears, it is because desire knows nothing of the separation between body and mind upon which the personality is founded" (Hocquenghem, 1993, p. 75). Guy Hocquenghem reminds us of Guattari's emphatic claim that "desire is constituted before the crystallization of the body and the organs, before the division of the sexes, before the separation between the familiarized self and the social field" (1996, p. 153). Temporality haunts seminality and futilely attempts to colonise and master desire. Hocquenghem describes sexuality itself as a tentative negotiatory practice of discursively wrangling the dissipative fluidity of desire. Desire for Hocquenghem, as it is for Guattari, comes before any speech and will therefore always remain in excess of discourse, taking desire as before, beyond and thus entirely outside the temporalisation of libidinality. This temporality can be understood variously as the narrativisation: of sexuality; of sexual subjectivity as psychologically, biologically and psychoanalytically incremental; of sexual acts as unfurling in time; of projects of obsession, romance and seduction; or of the development of thought in the theorisation of desire. Sexuality gives desire an outcome, sexuality thus is its own money shot of desire, subjugating desire to a subjectivity with an object and limiting its affects through temporality, insinuating causality.

Time, of course, can flow either way - "I desire, therefore I will act thus" can also be "I acted thus because of my predetermined sexuality". Time limits desire to excavation, thought to knowledge, imagination to reason and ejaculate to the sexually orgasmic and fertilising narrative. A fertile heterosexual will always be a heterosexual, a fertile homosexual will always be a potential heterosexual breeder, but an infertile heterosexual is not necessarily a heterosexual for they are removed from this confining structural framework of temporalisation and futuristic intentionality. "Desire is always 'outside' ... Once there's heterosexuality ... there's no more desire" (Guattari, 1996, p. 59). Sexuality is the desire for an outcome and is entirely estranged from desire in any way related to pleasure or libidinality. However, in perhaps a perverse turn, we wish to return to a claim which reminds the body that it is a body, in that certain kinds of desiring interaction can result in insemination and possibly birth.

As corporeal diagrammes without permanent structure and much to the disappointment of postmodernity in general, there are some bodies which adamantly deny majoritarianism, which are loath to identify simply as heterosexual but which ascribe their desire to the world of Guattari's 
asemiosis. Yet, nonetheless, the desirous flows of these bodies result in the act of vaginal-penile intercourse, which can lead to the possibility of fertilisation. Possibility attends to the finitude of any outcome: fertility phantasises reproduction; infertility guarantees potentiality, and what is produced is a germinal unfurling of desiring bodies in an encounter. Politically, the majoritarian should be responsible for addressing oppressive practices and active in non-co-optive or fetishistic becomings-minoritarian. If we seek to liberate desire from time, we must also liberate the politics of sexuality, which would mean seeking a sexual theory that engages with pre-subjective, premajoritarian/minoritarian bifurcation. Sadly, certain attempts have resulted in reifying the very statuses that these admirable aims seek to deconstruct, ${ }^{1}$ however, some volatile results have occurred in the new straight queer (see e.g., Thomas, Aimone and McGillivray, 2000).

Actively making oneself infertile challenges the unseen but spectrally enormous element of the phallus as ultimately productive and heterosexual vaginal intercourse as in the service of this production. Defiant and celebratory acts of becoming sperm-free necessitate a rethinking of heterosexual intercourse in its new role in queer theory, or as a minoritarian practice. It also means that heterosexual acts are truly delivered from their biological reminders. In contrast, minoritarian sexual politics remain plagued - no matter how queer heterosexual acts imagine themselves - with the practicalities of contraception. Infertile semen potentially relate only to the social issues associated with disease when it has been redeemed from its fecundity. Michael Johnson Jr. identifies what he calls the "ejaculation imperative" in the realm of heterosexuality, homosexuality and, most importantly, homosociality, which functions as a mandate by which masculinity is judged, whereby "the superficially seeming, innocuous physiological function becomes powerfully equated with the masculine ideal" (2010, p. 239).

The relationship between ejaculate and homosexuality, from "jerk circles" to barebacking, is beyond the scope of this work. However, resonant with homophobic, anxiety-driven biopolitical discourses, heterosexual sperm-free semen - now without the possibility of fertilisation - belongs to the realm of disease alone and for that reason is abjected from its sacred signification. The privileging of the visual is also shared in both the heterosexual and the homosexual overvaluation of semen; the vindication of non-fertile semen may redeem it somewhat from this privileging of the visual, however, through the tactical use of the act of heterosexual intercourse. Pragmatically, in heterosexual intercourse, the more likely fertilisation is, the less likely one is to see the spectacle of 
ejaculation. We utilise these somewhat awkward details not to bring a template of heterosexual intercourse into some kind of redemption as being the queerest of new queers, but simply in order to remind us that the very quietest, ordinary and most default of acts accepted as normal by society actually goes against many phallologocentric imperatives when enacted between two bodies as coupled intensities (rather than performative spectacles).

Desiring acts and activities cannot be thought without recourse to the body, nor would we wish them to be. Irigaray beautifully attempts to negotiate the residual physiological inevitabilities within desire in her shift from the use of the term "sexual" to "sexuate" difference. She states:

I use the term 'sexuate' rather than 'sexual' in order to avoid the all too frequent confusion between sexuate identity and sexual choice. Sexuate identity is more basic and it is more determined by birth than sexual choice. It is determined by both the morphology of the body and the relational environment which goes with this body ... it implies making love either inside or outside one's own body and with a specific relationship with mucous and engendering ... In any case, the fact that sexuate identity is both connected to the body and a relational context ensures that is from the beginning both nature and culture, a culture that is or not, appropriate to one's own nature and that thereby favours or prevents the growth and blossoming of this nature. (2008, p. 142)

Irigaray evokes a term which is returning to philosophy, liberated from its associations with biological essentialism, which is now acknowledged as always having functioned on the cultural cooption of imagined absolutes in order to vindicate power dissymmetry. Through the notion of "sexuate identity" and "sexuate difference", she offers a means of thinking desire and the corporeal experiences of desire that can remain anchored in the body. Neither do they become lost in abstraction or subjected to physical determinism. "Sexuate" assists in the conceptualisation of heterosexual intercourse as removed from the imperatives of a culture obsessed with oppositional identities and driven by the fantasy of the complementary relationship of sperm-and-egg and testes-and-uterus. 
This term is biology which escapes knowledge, which evinces that the world, like desire, is before, beyond and atemporally in excess of our capacity to apprehend it. It may be the subject of science; it is certainly the host to the human parasite; it is Nature. "Nature is reduced to human nature, which is reduced to either history or reason. The world has disappeared ... Curiously, reason acquires in the legal sphere a status quite similar to the one it had acquired in the sciences: the laws are always on its side because it founds law" (Serres, 2002, p. 35). In the contemporary desire to rectify some of the damage perpetrated by humanity, to turn our address to ecological and environmental issues, welfare and the redistribution of freedom, we still fail to allow natural law (which we still identify as external to the human, yet only we demarcate, separate and define externality) to govern, because natural law must be resonant with human logic. For the human, a law of nature is unthinkable. Nature itself in its current conception is a phantasy precisely because it is inconceivable; as Serres states, the world does not exist. We champion the vasectomised body - indeed, what could be simpler for allowing the world to exist, than the cessation of human life within it?

Sexuate identity, as Irigaray claims, has an intimate relationship with mucous. It is a constitutive factor of a relationship between bodies where that relation can be described as mucous. She states:

a genesis of love between the sexes has yet to come about, in either the smallest or the largest sense, or in the most intimate or political guise. It is a world to be created or recreated so that man and woman may once more or finally live together, meet, and sometimes inhabit the same place. ... It is a threshold unto mucosity. Beyond the classic opposites of love and hate, liquid and ice lies this perpetual half open threshold, consisting of lips that are strangers to dichotomy" (1992, pp. 174, 175).

The absence of reproductivity and semen as mucosal consistency constituted by different elements in one fluid offers proximity without likeness, phallologocentric colonisation and the reduction of all to economies of solids and absences. Irigaray's two lips model - most frequently associated with the vulva and female genital morphology as proliferation, multiplicity and indeterminacy, the viscosity of which is that of mucous - can enjoy here an unusual and unnatural participation with male genitalia and sperm-less semen. The penis has its own multiple labiality, just one example 
being in the fraenulum's meeting with the corona, the site which produces mucous and which contains the aperture. The morphology of folds and fissures commonly associated with the feminine is ablated by the organizing principles of solidification in phallic operations. But the more refined and minute elements of male morphology, like the voluminous multiple impotence of semen without sperm, open out their fleshy folds to infinity.

Georges Bataille's poem "The Penis Hole" emphasises both the jouissance and the connectedness of a dephallicised penis to all erotogenising, morphological sites: "The penis hole is laughter / and the ass crack the dawn" (2004, p. 73). One of his Archangelical fragments celebrates "starburst of laughter / morning of great sun" (2004, p. 153), and a poem fragment reads, "I have searched for what we do / when we sacrifice / and climax / and laugh" (p. 82). The image of the laughing orifice, suggestive but not fully defined, recalls the opening and closing of the two sets of two lips in Irigaray as they massage each other in various desirous and joyful configurations: "Two lips kissing two lips: openness is ours again... The passage from the inside out, from the outside in, is limitless ... Are we unsatisfied? Yes, if that means we are never finished. If our pleasure consists of moving, being moved, endlessly" (1985, p. 210). Temporality is suspended and extended, finality is deferred and dismissed.

Bataille's Divine Filth frequently oscillates between terror at the jubilance of sex experienced by the atrophied majoritarian male and indulgence in that kind of masculinity's sacrifice in pleasure as a kind of chaotic laughter. Furthermore, it shows a shift from phallus to multi-planed flesh, speech to laughing silence and orgasm as finitude or goal to chance or luck. He describes Zen as the nothingness which neither lacks nor describes nothingness and which is constituted by the coming of luck. In this way, orgasm can be configured so that neither it nor its association with semen are dismissed, while delivering it from its situatedness as the temporal and incremental causal finitude of desire. The penis, configured as planes with mucosal consistency and labial folds, creates a third connection, joining with the feminine labial folds to the lips of the mouth which speak as inbetween: where the air connects the interim between two voices, two bodies, two sets of (at least) two; and defined by the voluminous, irresistible connectivity which gives each its unique consistency, and without which each is in solitude and thus without a constituting ethics of difference. Irigaray writes: 
Pressed against each other but without any possibility of suture, at least of a real kind, they do not absorb the world either into themselves or through themselves, provided they are not abused or reduced to a mere consummating or consuming structure. Instead their shape welcomes without assimilating or reducing or devouring. $(1992$, p. 175)

The penis made mucosal and sexuate, and the entirety of male morphology, creates a sympathetic proliferation with feminine lips and speaking lips. Where sperm and the phallus do not reduce and assimilate female sexuality to the economy of one, and an anti-"heterosexual" act of sexuality denies the proliferative folds of femininity for a devouring of all male morphology, the mucosal relations of these many folds of labial flow open out toward infinity, both to nature in an address to the plenitude found in all bodies (and which is robbed from bodies through signifying regimes) and toward the divine in the silence that comes from pleasure which has been delivered from language and its limits, philosophical, biological or social. Irigaray calls such a form of interproximity angelic: angels "open up the closed nature of the world" (1992, p. 173) and thus an angelic and mucosal relation is boundless and exultant.

For Irigaray, gesture is the language of angels, and they both reflect fallen carnality - that which awakened the world to sexual difference in the first place - and the sexuality to come - that which is delivered from phallic isomorphism and any moral law of God. Being between these times, any encounter of a mucosal kind must be outside of this between-time as well; thus, mucosal encounters of sexual difference are divine because they are outside of present time and part of a contraction of imagined past and unthought future, in sharp contrast to the predetermined retrospection and anticipation of the semen-as-sperm-and-only-sperm encounter.

Where abjection sees mucous and the corpse belonging to the same order of interim and inbetween, Irigaray states instead: "Mucosity ought no doubt to be thought of as linked to the angel, while the inertia of a body deprived of the mucous and the act associated with it is linked to the fallen body or corpse" (1992, p. 174). Against the atrophy of solids found in physics, which stiffens the penis into its own inert rigor mortis, structuring sexuality, stemming flows and damming desire, mucosity exploits angelic relations as always in movement even outside of time: "Movement, posture, the coming-and-going between the two. They move - or disturb? - the paralysis or 
apatheia of the body or soul, or world. They set trances or convulsions to music, and lend them harmony" (Irigaray, 1992, p. 174).

Semen without sperm is fluid without solid, sex as perturbation, harmony without narrative or regulating melody. Most crucially, it refuses the one symbol which Irigaray sees as representing the "evidence" of the false belief in sexual difference being already in harmony - the child. The spectre of the child haunts and constitutes the spectral elements of sperm. There are no objects produced in the most creative of sexuate relations. With any possibility of the child taking up the symbol of alliance, the sexuate ethics of heterosexual intercourse as being an angelic, unnatural participation are prevented. Like the object icon of the sperm, the phallus and the money shot, reproductivity leading to a symbolic child defers heterosexual sexuate ethics to what is produced in place of the relation.

Configuring male sexuation through a mucosal seminality addresses two issues faced by a sexuate ethics. First, it rejects the overreliance on the feminine to forge and emphasise proximity to the divine and the natural (not in the theistic sense but in the sense that the divine is life liberated from capital, linguistic, theistic and other epistemological regimes). Secondly, it shows an accountability for the detriments and oppressions of phallologocentrism in the need for such mucosal masculinity to emerge.

Semen has come to stand for masculinity, virility, linear temporality and the assurance of pleasure and fulfillment; it is an overdetermined substance theoretically and representationally. Any project that attempts to think seminal fluid anew must guard against replacing these existing cultural fantasies with new and potentially just as restrictive singular meanings; it must stake an adamant refusal to privilege temporalised sexuality over the vicissitudes and imaginative flights of desire. However, Murat Aydemir makes a connection that, when explored in conjunction with our aims in this article, may offer the possibility of semen as asignification which opens up meaning rather than foreclosing it. The whiteness of semen, he notes, has come to the fore in several literary and philosophical musings on the subject, including Bataille's association of semen with the Milky Way in The Story of the Eye and Aristotle's designation of this whiteness as playing a primary role in setting it apart from other bodily fluids (2007, p. 12). Whilst Aristotle's association of white with purity is located within a well-documented tradition of philosophical tyranny, whiteness may be 
repositioned so as to act not only as the absence of colour, but as a modality which may deinscribe existing forms of signification. As Aydemir suggests, Jacques Derrida's analysis of Stéphane Mallarmé's work in Dissemination opens up an interesting trajectory that intersects with the reconfiguration of semen as blank mucous. Derrida states: "what ruins the 'pious capital letter' of the title and works toward the decapitation or ungluing of the text is the regular intervention of the blanks, the ordered return of the white spaces, the measure and order of dissemination" (2004, p. 193). Lawlor's "'place' becomes 'spacing'" is once more evoked. Whiteness acts not as an assurance of purity or elevation, but as "an active force of erasure, blotting out or whitening the text" (Aydemir, 2007, p. 24). The whiteness of semen bears no relation to its assumed status as reproductive fluid and, indeed, against Aristotle's assertion of this as a unique characteristic, it calls to mind cervical mucosal secretions as much as those of the male, denying the connotations of strictly masculine "purity" or "virility" that would fit neatly within the normative frameworks of sexuality. Instead, from this perspective, the whiteness of mucous taken not as spectacle or as symbol of reproductive force acts as almost as a tabula rasa - a de-inscription of existing understandings and the manifestation of white as "a germinal or seminal blank" (Derrida, 2004, p. 194). This germinal blank refers not to any pre-inscribed meaning but, rather, to the potentiality of multiple and open meanings, or to no coherent meaning at all. Whiteness as silence, potentiality and infinite gesture.

Angelic mucous, germinal whiteness and aproductive heterosexuality contribute to an ethics that aims to render redundant the socio-cultural emphasis on reproductive sexuality, goal-oriented masculinity and the futurity of the phantasmic Child. Instead, it strives towards multi-directionality and non-totalization. "At the heart of all ecological praxes there is an a-signifying rupture, in which the catalysts of existential change are close at hand" (Guattari, 2000, p. 30). This article aims to create such a rupture and thus argues for an anti-breeder philosophy that engages with the concerns of ecosophy in formulating a more responsible relationship between nature and culture, critiquing the centrality and privilege that has been given to the category of "the human". To cast aside the ruptured and deformed cadavers of humanist narratives entails not the adoption of new experimental but nonetheless pragmatic prescriptions of sexuality, but the jubilant embracing of a creative and formless desire. From an ethical perspective, the abjection of the blank semen is symbolic of the even more abject concept (even in the queerest circles) of the cessation of reproduction as integral to any actualisation of ecosophy. 
In Spinozan ethics self-understanding as meditation on the mind's eternity posits the self and mind as continuously germinal, a perpetual beginning which unravels via multiple trajectories within the mind's multiple intra-affects and their collisions and mutations with the affects of others. The self lacks nothing, it is an eternity in space, without lamentation for imminent death and therefore in no need of a future which is configured via the substitute phantasy of the Child. For Spinoza, will has no absolute beginning, nor any established stasis, nor a perceptible end - it is maintenance as life without inherent qualities or essence. Desire understood as the premise of will in poststructural philosophy is thus constituted in the same way - outside of time and devoid of reducible essence, incapable of reproduction, either of act or object. If what we claim to know as "human" life were to cease, far from a suicidal, extinctionist death, life as immanent living would be irresistible as it would have no alternative, no deferral to an expected coming generation, no future signifier.

The gradual cessation of human life on Earth and in the Universe marks the beginning of the contemplation of the eternity of life affects, of the life of all ecosophical cosmic interaction to which philosophies of desire attend in their association of desire with the divine and with ethics. Encouraging the cessation of human occupation of Earth and space is the opposite of being against life. Human knowledge of life, in a similar manner to human knowledge of sexuality and gender, sacrifices that life, conceptually and actually. Neither are capable of negotiating difference. Life lived knowing we are the last generation of life is life lived accountably and in joy at our micropolitical address of affects - diminishing and expanding - toward making all connectivity of life as liberated from the detrimental effects of human population as possible.

Ethically, this new life, lived in the worlds to which our finitude introduces us, make us live differently; this is life configured in wondrous unthought-of ways that benefit Nature through our becoming more hospitable to difference, including our own which has been co-opted by the law of the human. We are less parasitic, more creative and productive in our libidinal, desiring connections and the opportunities of expressivity we encounter from a world constantly territorialised anew. This begins with the quiet moments of desiring encounters such as heterosexual intercourse which previously occupied the zenith of the maintenance of traditional paradigms of sexuality and gender but now become strange in their orientation toward extinction as the liberation of Nature. 
"Never forget the place from which you depart, but leave it behind and join the universal. Love the bond that unites your plot of earth with the earth, the bond that makes kin and stranger resemble each other" (Serres, 2002, p. 50). Resemblance without homogenization, nature as unnatural, and love without structuring relation or condition are subtle, gracious interactions with the earth, earths, life intensities. Extinction destroys nothing, it is everything the earth is left without in the cessation of life as human, and human lives converted to living-ness, in desire, in divine difference. Thinking immanent life extinguishes any obsession with the futurity of extinction, which comes to stand in for the Child if blank semen remains in the realm of the reproductive. Instead, it

brings into being other worlds beyond those of purely abstract information, to engender Universes of reference and existential Territories where singularity and finitude are taken into account by the multivalent logic of mental ecologies and by the group Eros principle of social ecology; to dare to confront the vertiginous Cosmos so as to make it inhabitable; these are the tangled paths of the triecological vision. (Guattari, 2004, p. 67)

Angelic mucosal sexuate ethics open the infinity of the world, this world, without the need to replace the heterosexual relations of desire hitherto seen to perpetuate oppression, compulsory reproduction and normativity with an equally structured and possibly recuperative version of transgressive sexuality for its own sake. Heterosexuate ethics shows alterity in all desire which dissipates into desire for this life and this world as Cosmic potentiality.

\section{Notes}

1 Bob Pease, for example, claims: "We should not leave it to gay men and lesbians alone to deconstruct heterosexuality", yet follows with, "I know that I continue to learn from my gay and lesbian colleagues and friends" (2010, p. 128).

\section{Bibliography}

Aristotle, 1943. The Generation of Animals. Trans. and ed. A.L. Peck. Cambridge, MA: Harvard University Press. 
Aydemir, M., 2007. Images of Bliss: Ejaculation, Masculinity. Meaning. Minneapolis: University of Minnesota Press.

Bataille, G., 2004. Divine Filth. Trans. M. Spitzer. London: Creation Books.

The Bible. King James version.

Deleuze, G. and Guattari, F., 1987. A Thousand Plateaus: Capitalism and Schizophrenia 2. Trans. B. Massumi. London: Athlone Press.

Derrida, J., 2004. Dissemination. Trans. B. Johnson. London: Continuum

Edelman, L., 2004. No Future: Queer Theory and the Death Drive. Durham: Duke University Press.

Guattari, F., 1996. Soft Subversions. Trans. D. L. Sweet and C. Wiener. New York: Semiotext(e).

_ 2000. The Three Ecologies. Trans. I. Pindar and P. Sutton. London: Continuum.

Hocquenghem, G., 1993. Homosexual Desire. Trans. D. Dangoor. Durham, NC: Duke University Press.

Irigaray, L., 1985. This Sex Which Is Not One. Trans. C. Porter. Ithaca, NY: Cornell University Press.

__ 1992, Sexual Difference. Trans. S. Hand. In M. Whiteford, ed., The Irigaray Reader. London: Blackwell.

—_ 2008. Conversations. Trans. S. Pluhacek. London: Continuum.

Johnson Jr., M., 2010. 'Just Getting Off': The Inseparability of Ejaculation and Hegemonic Masculinity. Journal of Men's Studies 18(3), pp.238-48.

Kristeva, J., 1982. Powers of Horror: An Essay on Abjection. Trans. L. Roudiez. New York: Columbia University Press.

Lawlor, L., 2006. The Implications of Immanence: Toward a New Concept of Life. New York: Fordham University Press.

Pease, B., 2010. Undoing Privilege: Unearned Advantage in a Divided World. London: Zed Books.

Serres, M., 2000. The Birth of Physics. Trans. J. Hawkes. Manchester: Clinamen Press.

- 2002. The Natural Contract. Trans. E. MacArthur and W. Paulson. Ann Arbor: University of Michigan Press.

Thomas, C., Aimone, J. O. and McGillivray, C. A. F., eds, 2000. Straight with a Twist: Queer Theory and the Subject of Heterosexuality. Urbana, IL: University of Illinois Press. 